\title{
TRADIÇÃO E MODERNIDADE EM A CIDADE E AS SERRAS
}

Paulo Fernando da Motta de Oliveira

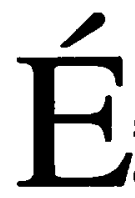

extensa a fortuna crítica de $A$ Cidade e as Serras. Mas, como por sinal ocorre com boa parte da produção de Eça posterior a Os Maias, os vários textos que analisam este livro possuem mais diferenças que semelhanças: entre as posturas extremas de Jacinto do Prado Coelho (1979, p. 172), que vê este romance como uma "obra 'datada', inactual", e de António Saraiva (1990, p.157), que em Tertúlia Ocidental o considera "uma obraprima", encontramos os mais discrepantes juízos e as mais distintas perspectivas analíticas, que acabam por produzir reflexões muitas vezes contraditórias e excludentes. Assim, se pretendemos aqui discutir o papel da tradição e da modernidade nesta obra, temas centrais em um livro que privilegia dois espaços relacionados culturalmente com estes dois conceitos, é fundamental que tentemos coordenar estas várias perspectivas, em busca de uma síntese que consiga minimamente repensar algumas das análises já realizadas no que elas possuem, em nossa perspectiva, de conclusões pertinentes sobre este livro. É isto que, mesmo que de forma parcial, pretendemos fazer neste artigo, tentando assim evitar um problema também comum nestas análises, $o$ de desconsiderar ou negar de forma global as conclusões anteriormente elaboradas.

Em uma obra narrada em primeira pessoa, como ocorre com $A$ Cidade e as Serras, a tarefa inicial para uma decodificaçāo minimamente consistente é a de definir as linhas básicas que configuram a instância narrativa. Em relaçāo a esta questão dois trabalhos, apesar de chegarem a conclusões em vários aspectos contraditórias, são fundamentais: o de Carlos Reis, e o de Frank F. 
Sousa. O confronto destes dois textos conjugado com algumas conclusões que a partir deles poderemos chegar nos mostrarão que o narrador de $\mathrm{AC} i$ dade $e$ as Serras pode ser analisado em dois níveis: aquele em que encontramos a sua imagem consciente, $e$ outro, não expresso, mas dedutível por uma série de indícios presentes em seu discurso, a partir do qual poderemos perceber que existe uma distância entre o que ele é e aquilo que imagina ser, distância que será fundamental no prosseguimento de nosso trabalho.

O primeiro nível acima apontado é definido, de forma bastante consistente, por Carlos Reis. Ele mostra que Zé Fernandes, enquanto narrador, assume o ponto de vista de uma personagem-testemunha. Assim, a história nos é narrada a partir do que, em cada um dos momentos da sua convivência com Jacinto, o narrador observa de seu amigo: são as características físicas, os gestos e vestuários deste que se transformam para o narrador, e através dele para o leitor, em sinais dos vários estados de espírito do protagonista. Basta lembrarmos, para comprovar este fato, que o físico de Jacinto decai, na mesma proporção em que ele se enfastia, e que o efeito do campo sobre ele também se traduz, em um primeiro momento, em uma mudança física, logo notada por Zé Fernandes, que o qualifica então de "um Jacinto novíssimo"(Queirós, 1950, p.188).

Se o que acima apontamos explicita em linhas gerais o papel assumido por Zé Fernandes enquanto narrador, será a relação, enquanto personagem, que ele possui com Jacinto, que terá maior importância para a análise que aqui pretendemos realizar. De início, ainda segundo Reis, o que o caracteriza, é um laço de amizade muito grande, que se conjuga, porém, com uma oposição ideológica em relação ao Jacinto citadino. Esta própria postura ideológica, porém, que o transforma em um defensor do campo, em oposição a seu amigo que, inicialmente, defende a cidade, sofre uma evolução ao longo da narrativa. Se, em um primeiro momento, por mais que discorde de seu amigo, Zé Fernandes não o critica, pois vê na escolha de Jacinto o esteio de sua felicidade - como afirma o narrador "nunca desalojarei um espírito do conceito onde ele encontra segurança, disciplina e energia"(Queirós, 1950, p.14-15) - conforme observa o protagonista decair vai explicitando de forma cada vez mais

Tradiçāo e modernidade ... Paulo Fernando da Motta de Oliveira - Págs. 155-171 
patente seus pontos de vista, explicitação que ganha seu produto mais acabado no longo discurso anticitadino que faz na colina de Montmartre. Assim, podemos concluir que a trajetória de Jacinto neste livro seria não apenas aquela que o leva da cidade às serras, mas a que o traz de um ponto de vista oposto ao mesmo ponto de vista de seu narrador. Além disto, enquanto Jacinto é um personagem em evolução, Zé Fernandes seria o polo fixo, sempre igual, do ponto de vista ideológico, ao longo de todo o livro, sendo portanto a voz narrativa, quando do momento da enunciação, ainda partidária dos mesmos valores que sempre teve. Assim, independentemente de como seja analisada a evolução de Jacinto, "não podemos deixar de atribuir um relevo fundamental à função eminentemente activa da testemunha que assiste ao desenvolvimento da curva evolutiva do herói da diegese" (Reis, 1982, p.242-243.).

Nesta perspectiva, se nos lembrarmos que, como afirmou Alexandre Pinheiro Torres (1989, p.54), no momento inicial do livro, "Para Jacinto, a cidade é já a Eutopia, embora (...) para Zé Fernandes ela não passe de Distopia", poderíamos concluir que as características da modernidade, típicas da cidade, seriam duplamente negadas nesta obra: elas não só trariam a infelicidade, em oposição à felicidade capaz de ser alcançada no campo, mas também fariam parte de um universo ilusório, de falsas verdades, cujo destino seria o de ser negado, como demonstraria exemplarmente a trajetória de Jacinto. Assim, o universo da tradição seria não só mais benéfico, mas também mais verdadeiro e duradouro que o da modernidade, fadado este a ser superado na busca por uma felicidade perene.

Mas, como dissemos no início, esta perspectiva é apenas em parte verdadeira. Frank F. Sousa em seu artigo publicado na revista Queirosiana nota outros aspectos importantes sobre este narrador, que nos permitirão avaliar certas características desta obra que ainda não levamos em consideração. Este crítico parte de uma questão fundamental, a de saber em que medida Zé Fernandes pode, ou não, ser considerado um narrador confiável e, a partir dela, analisa uma série de características do discurso narrativo. Se, em nosso ponto de vista, não podemos concordar com todos os índices que aponta para a não confiabilidade deste narrador, aspecto que aqui não discutiremos 
por fugir dos objetivos deste ensaio, alguns elementos significativos nos permitem verificar que a postura anticitadina do narrador é mais uma imagem que este tem de si do que uma visão real de suas características, é um desejo que não se confirma na suapraxis. De início devemos notar que Zé Fernandes, na sua última viagem a Paris, apesar de sua critica à cidade, acaba por comprar "para os meus queridinhos de Tormes brinquedos consideráveis, tremendamente complicados pela Civilização, - vapores de aço e cobre, providos de caldeiras para viajar em tanques; leões de pele verídica rugindo pavorosamente, bonecas vestidas pelo Laferrière, com fonógrafo no ventre..."(Queirós, 1950, p.302-303), postura que, como afirma Sousa (1993, p.36), demonstra uma "duplicidade e contradição frente ao espaço urbano", já que acaba para levar para a Serra instrumentos da própria Civilização que renega. Mas não são apenas os brinquedos que leva. Quando salta do trem, já em Tormes, o carregador lhe traz uma série de papéis que havia nele esquecido: "Era uma papelada, de que me sortira na Estação de Orleans, toda recheada de mulheres nuas, de historietas sujas, de parisianismo, de erotismo." (Queirós, 1950, p.304). É curioso que Zé Fernandes tenha se sortido com esta papelada, se nos lembrarmos das imprecações que faz ao erotismo parisiense e às peças que viu sempre tendo por personagem principal uma cama, e se somarmos a isto o pesadelo que teve, no qual "em Tormes, se construíra uma torre Eiffel, e que em volta dela as senhoras da Serra, as mais respeitáveis (...) dançavam, nuas, agitando no ar saca-rolhas imensos"(Queirós, 1950, p.291), pesadelo que demonstra um medo de que a Serra seja contaminada pelos valores citadinos. É ainda mais curioso que ele acabe por ser um provedor, mesmo que não intencional, destes papéis que "derramavam através do mundo a sedução de Paris" (Queirós, 1950, p.304), já que eles acabam por ser recolhidos, após serem deitados fora por Zé Fernandes, por Pimenta, o chefe da estação, sendo assim o próprio Zé Fernandes um divulgador de valores que, aparentemente, tanto renega.

Se em relação aos brinquedos e aos papéis temos um personagem que trás para a Serra elementos da Cidade, Sousa (1993, p.37) aponta que "de forma mais subtil, a cidade chega até aí [à Serra] devido às histórias que Zé

Tradição e modemidade ... Paulo Fernando da Motta de Oliveira - Págs. 155.171 
Fernandes conta sem cessar". Ou seja, os dois casos citados acima podem ser vistos não como situaçōes isoladas, mas como a concretização de uma postura que, através de suas histórias, é recorrente. Assim, os próprios atos e palavras deste personagem parecem desmentir a postura anticitadina que ele adota de forma tão radical em seu discurso. Como bem nota Sousa, parece que aquilo que caracteriza Zé Fernandes é o fato de sempre desejar, e em certo sentido idealizar, o espaço em que não está, e acabar por se cansar, mais cedo ou mais tarde, dos espaços que habita. Assim, por exemplo, quando está para deixar Paris com Jacinto, já idealiza a cidade que antes tanto renegara, e afirma: "quase me pesava não ficar sempiternamente rolando, ao trote rimado das éguas perfeitas, no rebrilho rico de metais e vernizes, sobre aquele macadame mais alisado que mármore, entre tão tentadora frescura, cruzando uma Humanidade fina, de elegância bem acabada, que almoçara o seu chocolate em porcelanas de Sèvres ou de Minton (...)" (Queirós, 1950, p. 146). Por outro lado, após cinco anos no campo que fora tão idealizado por ele em Paris, acaba por sentir "no corpo como um começo de ferrugem, que o emperrava, e, certamente, algures, na minha alma, nascera uma pontinha de bolor" (Queirós, 1950, p.288) o que o leva de novo a Paris. Mas, uma vez lá, levantará como hipótese ser o "bolor da velhice" que não permite que ele se divirta na "deliciosa cidade"(Queirós, 1950, p.301), retornando mais uma vez, que diz ser a definitiva, ao campo.

Se estes vários indícios, espalhados pela narrativa de Zé Fernandes, certamente põe em questāo a sua aparente total adesão ao campo, não nos parece que a partir disto possamos concluir que a história de Jacinto trata-se de uma "solução tipo conto-de-fada-que acaba bem" (Sousa, 1993, p.41) e que a modernidade do livro se deva apenas à "problematização da existência repleta de ambiguidade e carecendo de uma solução definitiva, reflectida na figura de Zé Fernandes" (Sousa, 1993, p.42). De fato o problema é aqui de outra ordem, e cremos que só ganha seu verdadeiro significado ao contrapormos as trajetórias de Jacinto e de seu amigo. Ao fazermos isto podemos verificar que enquanto o segundo se caracteriza pela mobilidade, o primeiro está no polo da permanência. Com isto queremos indicar que Zé Fernandes é, em 
A Cidade e as Serras, justamente aquele personagem que ao longo da narrativa se encontra, todo o tempo, circulando entre os dois espaços que nela são configurados, a Cidade e as Serras, enquanto que Jacinto se fixa, nos dois segmentos da mesma, em cada um dos espaços que habita. Se para o protagonista temos uma única viagem, que o leva de Paris a Tormes, Zé Fernandes é aquele que, estando em Paris, vai a Tormes e, estando em Tormes, vai a Paris. Mais que isto ainda. É aquele que, em Paris, sente saudade e idealiza a vida no campo, mas que após estar algum tempo no campo, sente-se enferrujar, e necessita de um retorno a Paris. É aquele que em Paris fala de Tormes, e do quanto é boa a vida no campo, e em Tormes conta as maravilhas de Paris.

Parece-nos bastante significativo que, neste livro, tenhamos assim dois personagens que são, ao mesmo tempo, móveis e imóveis. À mobilidade ideológica de Jacinto se conjuga uma imobilidade espacial, uma fixação em cada um dos espaços escolhidos, à aparente imobilidade ideológica de Zé Fernandes se conjuga um constante vai-e-vem, que o joga do campo à cidade e desta ao campo. De fato, como bem notou António José Saraiva (1990), estamos diante de um procedimento recorrente na obra de Eça, que é o uso do duplo. Jacinto e Zé Fernandes são, claramente, dois personagens que se encontram diante de um problema central que, se possui uma tradição literária em Portugal que remonta a Sá de Miranda, ganha especial relevo para a cultura portuguesa do século XIX: a cisão entre o campo e a cidade, que nesse século significa a cisão entre o tradicionalismo português e a modernidade Européia, problema a que estes dois personagens dão, podemos agora notar, respostas antagônicas. Por trás da capa que se outorga de um defensor do campo, e consequientemente da tradição, temos em Zé Fernandes de fato um personagem que não consegue modificar a realidade campestre, no que ela tem de problemático, nem deixar de possuir a postura de um admirado basbaque diante da civilização. Sem viver em profundidade o brilho e a desgraça de cada uma das realidades, é-lhe vedada a solução encontrada por Jacinto. Como bem notou João Medina, no seu retiro na serra, Jacinto "dota o seu povo de farmácia, médico, creche, escola e as luzes mínimas sem as quais a Serra se bestifica e acaba por ser meramente vegetal"(Medina, 1974, p.153), ou seja, 
atinge uma síntese que lhe permite a felicidade. Buscar entender o sentido desta síntese, enquanto uma resposta possível para a dicotomia entre campoe cidade, parece ser assim fundamental para entendermos em que medida as respostas de Zé Fernandes e Jacinto se diferenciam, e o significado que cada uma delas possui. Torna-se assim fundamental analisarmos com maior vagar alguns aspectos da trajetória de Jacinto, para que melhor possamos diferenciála da que caracteriza Zé Fernandes.

Alexandre Pinheiro Torres, em seu estudo sobre As Cidades e as Serras, nota que relação de Jacinto com a cidade possui, para além da trajetória que o leva a seu abandono, uma outra bipartição, que até então não havia sido estudada. Ele aponta que, no início, Jacinto, em sua relação com o mundo, vive segundo o código edênico, que pressupõe uma "ausência de conflitos entre o homem e o espaço, ou seja, a harmonia entre os sujeitos e os seus objetos" (Torres, 1989, p.51). Como narra Zé Fernandes, "[Jacinto] Era servido pelas coisas com docilidade e carinho; - e não recordo que jamais lhe estalasse um botão da camisa, ou que um papel maliciosamente se escondesse dos seus olhos (...). E no Céu as Nuvens, pejadas e lentas, se avistavam Jacinto sem guarda-chuva, retinham com reverência as suas águas até que ele passasse..."(Queirós, 1950, p.10-11). Ou seja, "os objectos que representam a Cidade, que podemos classificar de 'culturais', coexistem num plano de harmonia total com o sujeito deles, ou seja, Jacinto. As 'coisas' servem-no 'com docilidade e carinho' (...). Podemos mesmo acrescentar (...) que os 'objectos naturais' que se contrapõem aos 'culturais', e, por tal, designamos tudo o que é Natureza, (...) comportam, em relação a Jacinto, o mesmo tipo de conexão harmoniosa" (Torres, 1989, p.51-52). Porém Jacinto, pouco depois, "comete o erro de separar (...) Natureza e Cultura, e proclamar a superioridade esmagadora desta última"(Torres, 1989, p.52), o que o levará a considerar que a felicidade só poderá ser alcançada pelo homem superiormente civilizado, aquele que "robustecendo a sua força pensante com todas as noções adquiridas desde Aristóteles, e multiplicando a potência corporal de seus orgãos com todos os mecanismos inventados desde Terâmenes, criador da roda, se toma um magnífico Adão, quase omnipresente, quase omnisciente, 
e apto portanto a recolher dentro duma sociedade e nos limites do Progresso (...) todos os gozos e todos os proveitos que resultam do Saber e do Poder ..."(Queirós, 1950, p.12). Partindo desta perspectiva, Jacinto construirá um paraíso artificial, em que "o 'artificial' corrigirá as deficiências do 'natural', do mesmo modo como o telescópio complementa a visão imperfeita, e, portanto, 'infeliz' do ser humano"(Torres, 1989, p.53). Esta cisão entre o 'objeto natural' e o 'objeto artificial', com a inegável supremacia do segundo, ganha sua imagem mais bem acabada no passeio que Jacinto e Zé Fernandes fazem à floresta de Montmorency, em que o primeiro vê a Natureza não domada como fonte de hostilidade e perigo.

Assim o 202 é, em vários aspectos, o paraíso artificial criado por Jacinto, o espaço em que a sua concep̧̧ão da vida e da felicidade ganha concretude. Nesta perspectiva, as avarias que sofrem os vários objetos do 202 ao longo da primeira parte da narrativa produzem um desprestígio do objeto cultural, que acabam levando-o à queda, desprestígio e degradação que o são do próprio Jacinto e da visão que tinha do mundo. Quebrada a relação homem/ objetos, quebrado o código edênico que regia a vida do protagonista, a alternativa que lhe sobra é a da substituição deste código edênico por outro, o de Tormes, de que Zé Fernandes possui a chave.

Mas, se até aqui concordamos com a análise de Pinheiro Torres, parece-nos que ele não leva suas conclusões às últimas consequiências, e não analisa a segunda etapa da trajetória de Jacinto com o mesmo cuidado que fizera na primeira. Preocupado em ver no livro uma crítica às concepções de Proudhon, Torres acaba por não perceber que existe, nas duas etapas da vida de Jacinto, um espelhamento e uma homologia muito significativas. Se, ainda seguindo este crítico, concordamos que Jacinto chega a seu novo Éden despido de todos os objetos culturais, um novo Adão reentrado na natureza, devemos notar que também este paraíso se quebra, da mesma forma como os objetos do 202 sofriam avarias. Estaquebra ocorre no dia em que é surpreendido pela chuva, dia em que o paraíso bucólico erigido na imaginação de Jacintoé duplamente negado no seu confronto com a realidade. De início pela própria chuva inesperada, momento bastante significativo pois, se como notamos no

Tradiçāo e modernidade ... Paulo Fernando da Molta de Oliveira - Págs. 155-I7I 
início deste trabalho, é através dos atos do protagonista que o narrador lê o seu estado de espírito, neste momento ele nos indica um súbito retorno de características do período infeliz da cidade: "E Jacinto, na borda do carro, com os pés no ar, cofiava os bigodes húmidos, palpava a face onde, com espanto meu, reaparecera a sombra, a sombra triste do 202!"(Queirós, 1950, p.229). É justamente neste momento que aparece "por trás da parede do alpendre um rapazito, muito rotinho, muito magrinho, com uma carita miúda, toda amarela sob a porcaria"(Queirós, 1950, p.229). O que se segue é o conhecimento que Jacinto toma da pobreza, ironicamente pontuado pela fala de Zé Fernandes, que indica claramente para o fato da Serra não ser o Éden: "Homem! está claro que há fome! Tu imaginavas talvez que o Paraíso se tinha perpetuado aqui nas serras, sem trabalho e sem miséria..."(Queirós, 1950, p.230-231). Porém, diferentemente do que ocorreu na cidade, neste momento Jacinto assume uma postura ativa, e reconstrói o paraíso que havia sido avariado por suas descobertas. Como ele afirma "Vi a chaga! Mas enfim, esta, louvado seja Deus, é das que posso curar!"(Queirós, 1950, p.239). Esta reconstrução, porém, é feita pela incorporação de objetos culturais no mundo natural, entre os quais alguns aparelhos modernos e úteis como o telefone, que possibilitaria o contato não só com Zé Fernandes e com seu sogro, mas também com o médico e a botica. Ou seja, em certo sentido, a trajetória de Jacinto é cíclica, e a reconstrução que ele estabelece é a da criação de uma nova unidade entre os objetos naturais e os artificiais, que existia já no início do livro, e que fora perdida após a cisão que é estabelecida entre estas duas categorias de objetos.

Esta reconstrução, porém, cria um novo código edênico que não é dado, como o do início do livro, mas construído. Não são as coisas que se dobram, por sua vontade, à de Jacinto, mas este que, através de seus atos, as ordena de forma harmoniosa. Devemos aqui ressaltar que, se não concordamos com vários aspectos da análise que António Sérgio faz deste livro, pois não achamos que "a antítese queirosiana de Cidade-Serra (ou de Civilização-Simpleza) foi uma falsa aparência com que a imaginação o iludiu" (Sérgio, 1980, p.67), perece-nos inegável que a redenção final de Jacinto, como bem notou este

Boletim do CESP и. 17, n.21 , jan. / dez 1997 
crítico, se dá através do trabalho. Parece-nos que Sérgio também acerta ao considerar que existe, nesta incorporação de objetos culturais uma perspectiva bastante diversa da que Jacinto assumia em relação a estes objetos na cidade. Se lá ele tendia a "acumular noçōes, a ajuntar inventos" (Sérgio, 1980, p.67), no campo assumirá uma perspectiva qualitativa, assimilando apenas aquilo que, concretamente, traz melhoramentos importantes e significativos. São o trabalho e esta perspectiva seletiva que, como podemos notar, transformam um falso Éden bucólico em um Éden real e concreto, em que o tradicional e o moderno se conjugam em proporções adequadas, em que o campo, sem perder suas características básicas, sem chegar a ser enfeiado pela "hirta sombra cor de ferro e foligem" (Queirós, 1950, p.285) do progresso, incorpora melhoramentos técnicos necessários para acabar com a miséria que, contraparte de sua beleza, o caracteriza.

A partir desta trajetória de Jacinto podemos notar alguns aspectos fundamentais deste livro. De início esta análise parece indicar que uma leitura do tipo sociológica não pode dar conta desta obra, como por sinal já havia sido. notado por outros motivos, por João Medina (1974, p.125). Em um livro em que o código edênico ocupa uma posição central, em que o protagonista habita um Éden que se transforma em Hades, para após uma travessia atingir um novo Éden que, novamente, mostrará também possuir uma porção infernal que precisa ser modificada para que um novo espaço edênico possa ser construído, este sim definitivo, parece-nos inadequada uma postura crítica ideológica ou sociológica, por partir de um arcabouço teórico absolutamente distinto do da obra tratada. Com isto queremos indicar que sobrevalorizar o fato das melhorias que Jacinto realiza não se estenderem a suas outras propriedades, ou o de Jacinto ser um caráter politicamente conservador, como o fazem Alexandre Pinheiro Torres (1989) e Beatriz Berrini (1987), acaba por obscurecer as características mais importantes desta obra, que são de caráter simbólico e alegórico. O próprio Eça já havia qualificado este seu livro de "une nouvelle phantasiste" (Apud Matos, 1988, p. 147), onde, certamente, os personagens principais não são tipos sociológicos, frutos de uma dada situação social demarcada, como ocorre na fase realista deste romancista, mas simbo- 
lizam, como até aqui pudemos notar, duas posturas distintas na oposição campo/cidade, tradição/modernidade. Posturas cuja diferença poderá ficar ainda mais patente se confrontarmos a trajetória da construção edênica realizada por Jacinto com o papel de Zé Fernandes na narrativa.

Enquanto Jacinto constrói o seu Éden nas Serras, nele conjugando os objetos naturais com os culturais, Zé Fernandes em todo o livro nada consegue construir, e em certo sentido termina a sua trajetória na narrativa de forma muito próxima à que havia começado. A sua auto-imagem tradicionalista, de defensor do campo, em nada se altera, e a cisão, que apontamos, entre seus atos e esta imagem, continuam no final tão grandes como eram no início. Sem viver a cidade na profundidade em que a viveu Jacinto, sem ter de fato aprendido com a multidão de objetos inúteis a utilidade que alguns deles podem ter, na sua última visita ao 202, renega todo o progresso, e considera que "mais tarde outros homens, com uma compreensāo mais pura e exacta da Vida e da Felicidade, percorreriam, como eu, longas salas atulhadas com os instrumentos da Super-Civilização, e, como eu, encolheriam desdenhosamente os ombros ante a grande ilusão que findara, agora para sempre inútil, arrumada como um lixo histórico, guardado debaixo da lona"(Queirós, 1950, p.298), sem perceber que, como bem notou Frank Sousa, "neste discurso violento de ataque à modernidade tecnológica, Zé Fernandes também relega o telefone para a zona do inútil e do olvido"(Sousa, 1993, p.25), uma invenção que, então, já fora anexada às Serras por Jacinto, e cuja implantação fora por ele considerada como "razoável", "prudente" e "fraternal"(Queirós, 1950, p.285). Por outro lado, tendo tido como horizonte sempre possível uma fuga para Paris, antídoto já duas vezes utilizado quando o campo perdia seu significado, não sentiu nenhuma necessidade de transformar o campo, de nele criar um espaço de fato atraente, que o pudesse fixar de forma definitiva. Para ele a Serra é intocável, não só no que possui de belo, mas também no que possui de miséria. Se na cidade havia pregado em favor dos pobres que são espoliados, na serra fala da pobreza como se ela fosse natural. No seu tradicionalismo aparentemente ferrenho, mas que sempre tem Paris como um horizonte possível de fuga, $Z \in$ Fernandes nada modifica. 
Este confronto entre as posturas de Jacinto e Zé Fernandes pode nos levar a perceber o significado mais profundo desta obra, e a forma como ela se insere no conjunto da produção eciana.

Antonio Candido, em seu artigo "Eça de Queirós entre o campo e a cidade" considera que "Observada em seu conjunto, mesmo de maneira superficial, a obra de Eça de Queirós se apresenta em grande parte como o diálogo entre o campo e a cidade"(Candido, 1978, p.31), diálogo em que o primeiro, o campo, significa "tradicionalismo, economia agrária, sentido paternal nas relações entre as classes"(Candido, 1978, p.31) e a segunda, a cidade, "vida moderna, intercâmbios sociais intensos, participação na civilização capitalista do Ocidente"(Candido, 1978, p.31): Se aqui lembrarmos que um dos fortes anseios de alguns membros da geração de 70 foi, como sintetizou Antero em sua Causas da Decadência, o de fazer com que Portugal entrasse "outra vez na comunhão da Europa culta"(Quental, 1982, p.294), podemos perceber que a valorização do campo nas últimas obras de Eça, presente em vários textos - e que possui um de seus produto mais bem acabados, como tentei mostrar em outro artigo, em "Civilização" (Oliveira, 1997), conto que deu origem ao romance que aqui estamos analisando-significa simbolicamente uma mudança de perspectiva, em que a recuperação de valores tipicamente portugueses passa a ter um papel mais significativo do que a tentativa de aproximar Portugal da Europa, ou seja, da 'civilização capitalista do Ocidente'. Esta tendência percorre muito da produção eciana do último vintênio do século passado. Já em um artigo provavelmente escrito entre 1887 e 1888 (Cf. Medina, 1974, p.129), "O Francesismo", Eça mostra, de forma negativa, a grande influência que a França teve sobre a sua geração, influência que transformou Portugal em "um país traduzido do francês em calão"(Queirós, U.P., 1946. p. 397), país que "rompera com a tradição nacional, despindo-se de todo o traje português, para se cobrir - pensando, legislando, escrevendo, ensinando, vivendo, cozinhando - de trapos vindos de França"(Queirós, U.P.,1946. p. 408). Em carta a Oliveira Martins, de 26 de abril de 1894, o autor de Os Maias afirmava para seu amigo: "Tu reconstróis a Pátria, e ressuscitas, com estes livros [Os Filhos de D. João Ie A Vida de Nun'Álvares], o 
sentimento esquecido da Pátria. E não é pequeno feito reaportuguesar Portugal"(Queirós, C., 1946. p.248), afirmação que mostra o papel importante que então atribuía à recuperação das características nacionais. É justamente esta recuperação que aparece, ficcionalizada, já emA Ilustre Casa de Ramires, obra que começou a ser escrita em 1897, em que o decadente Gonçalo se reaportuguesa, após a assembléia de fantasmas, recuperando uma auto-confiança há muito perdida por sua raça e conseguindo assim partir para uma nova ordem de conquistas.

Porém, é importante que explicitemos, reaportuguesar Portugal não significa, de forma alguma, aceitar acriticamente as mazelas do país, ou tentar recuperar um passado que não mais existe. Como apontou no artigo "Brasil e Portugal", publicado originalmente noAtlântico em 26 e 29-12-80, para Eça "há duas espécies de patriotismo" (Queirós, 1945, p. 65), o dos que, como ele, "Respeitam a tradição, mas o seu esforço vai todo para a nação viva, a que em torno deles trabalha, produz, pensa e sofre: e, deixando para traz as glórias que ganhamos nas Molucas, ocupam-se da pátria contemporânea, cujo coração bate ao mesmo tempo que o seu"(Queirós, 1945. p. 65), e o dos que, como Pinheiro Chagas com quem nestes artigos 'conversa', "para quem (...) a pátria não é a multidão que em torno dele palpita na luta da vida moderna - mas a outra pátria, a que há trezentos anos embarcou para a Índia"(Queirós, 1945. p. 66), para os quais "amar a pátria é tomar a lira e dar-lhe languidas serenadas"(Queirós, 1945. p. 66). Nem tampouco 'reaportuguesar' significa sobrevalorizar a tradição, como podemos deduzir da carta que enviou a Alberto de Oliveira datada de 6 de agosto de 1894, quando da publicação de $A s$ Palavras Loucas, em que afirma, entre outros aspectos, que "não se curam misérias ressuscitando tradiçōes"(Queirós, C., 1946. p. 252) e pergunta a Alberto de Oliveira:"não lhe parece que o Nativismo e o Tradicionalismo, como fins supremos do esforço intelectual e artístico são um tanto mesquinhos?"(Queirós, C., 1946. p. 251). Nesta mesma carta chega até a considerar que a tendência tradicionalista na literatura já fora "largamente experimentado, durante trinta largos anos, de 1830 a 1860"(Queirós, C., 1946. p. 251), sem que isto tivesse servido seja para "o aperfeiçoamento dos 
caracteres e das inteligências"(Queirós, C., 1946. p. 251), seja para a renacionalização do país.

Cremos que é apenas dentro deste contexto mais geral que $A$ Cidade $e$ as Serras ganha seu verdadeiro significado, e que as trajetórias de Jacinto e Zé Fernandes podem ser plenamente decodificadas. Jacinto é, como bem notaram Beatriz Berrini(1987) e João Medina(1974), a partir de perspectivas por sinal bastante diversas, um português exilado em Paris. Apesar de ter nascido na França, está economicamente e mesmo afetivamente ligado à Lusitânia, aparentemente fala com mais freqüência o português que o francês, e ao lado dos periódicos franceses lê, também, os publicados no país de origem de sua família. Se aceitarmos esta perspectiva, podemos entender a cisão que efetua entre o objeto cultural e o objeto natural, que anteriormente indicamos, como um mergulho na concepção "européia", não portuguesa, na medida em que ao assumir esta perspectiva nega justamente o que, na economia do livro, a Serra possui de característico, a natureza. Assim a infelicidade que cada vez vai mais caracterizá-lo pode ser interpretada como um desligamento de suas raízes. Jacinto é, nesta perspectiva, Portugal em sua relação com a França, como Eça o enxerga no artigo "O Francesismo", e mesmo, em uma outra perspectiva que não nega a primeira, um símbolo de sua própria geração, que "por toda a parte levou o seu francesismo d'educação (...) e tornou este velho Portugal de D. João VI uma copia da França, mal feita e grosseira" (Queirós, U.P., 1946. p. 408). Se a França representa a modernidade, a civilização capitalista do ocidente, ela tem, de início, o grande defeito de não ser Portugal. Mas não apenas este. A França, como a enxerga Eça no artigo que já citamos, é em si decadente, e além de um brilho que vem de outras eras, de fato nada pode ensinar a Portugal. Este aspecto também aparece no romance. Como bem notou Marie-Helene Piwnik (1987), várias das caraterísticas dos personagens que cercam Jacinto em Paris os aproximam de forma clara das tendências do decadentismo francês que, certamente, é a corrente estética que traduz a decadência que então Eça visualizava no país. A viagem de Jacinto a Tormes, que João Medina equivale à de Ulisses retornando a Ítaca, assim, devolve Jacinto à sua terra natal, faz com que a planta artificialmente criada na

Tradição e modernidade ... Paulo Fernando da Motta de Oliveira - Págs. 155.171 
cidade possa viver no terreno que naturalmente lhe cabe. Se o livro aqui terminasse poderíamos até supor que existiria uma aceitação deste último Eça das características típicas e retrógradas do país, como, por sinal, parte da crítica tendeu, durante muito tempo, a considerar. Mas, como vimos, não é isto que ocorre. Jacinto elaborará, agora em seu próprio terreno, uma nova síntese. Síntese que lhe é possível, como antes afirmamos, por ter passado pelo espaço da modernidade, e ter aprendido o que ele possui de positivo e de negativo. Assim este novo equilíbrio não nega as tradições do país, não tenta apagar a sua história recente ou remota, como "parricidamente" Antero, em nome de sua geração, tentou fazer (Cf. Lourenço, 1982. p. 98). Mas ao mesmo tempo não aceita as tradições como um valor imutável. Esta aceitação acrítica, como o livro também o indica na figura de Zé Fernandes, não é uma solução, pois não só perpetua uma situação de miséria e degradação, mas se conjuga com uma aceitação da modernidade estrangeira como algo negado internamente, mas buscado como válvula de escape quando se necessita "recuperar as forças" do atraso. O estrangeiro, por diferente, ganha, para Zé Fernandes, o estatuto que Portugal, enquanto país exótico, possui para o resto da Europa, sem que este perceba a dicotomia em que se encontra.

Não devemos esquecer, porém, que esta obra é um romance, e não uma proposta programática para a possível solução dos problemas nacionais. Assim, importa pouco se as imagens decorrentes desta obra podem ou não servir de uma via possível de ressurreição de Portugal. Mais importante é podermos notar, como aqui tentamos demonstrar, que $A$ Cidade e as Serras parece se configurar como um momento de equilíbrio e apaziguamento dentro da produção eciana. Sem negar seu país em nome de um progresso outro, sem aceitar as suas misérias em nome de uma tradição que em si é puro imobilismo, Eça constrói uma grande alegoria em que, ao menos ficcionalmente, uma terceira via é configurada, em que o país, para se manter enquanto tal, consegue e precisa seletivamente progredir. 


\section{RESUMO}

Pretendemos aqui, atravês de um diálogo com algumas obras significativas da fortuna crítica sobre $A$ Cidade e as serras, pensar as relaçóes entre tradiçăo e modernidade presentes nesse romance.

\section{RÉSUMÉ}

Ce travail veut, à travers un dialogue avec quelques travaux critiques sur $A$ cidade e as serras, penser les relations entre tradítion et modemité dans ce roman.

\section{BIBLIOGRAFIA}

BERRINI, Beatriz. Jacinto, aristocrata nural. Colóquio Letras, 97. Lisboa: Fundação Calouste Gulbenkian, maio-junho 1987. p.26-36.

COELHO, Jacinto do Prado. A tese de "A Cidade c as Serras". 2.ed. A Letra e o Leitor. Lisboa: Moraes Editores, 1979.p. 169-174.

COELHO, Jacinto do Prado. Eça, escritor ambíguo?.Ao Contrário de Penélope. Amadora: Bertrand, 1976. p.189-193.

LOURENÇO, Eduardo. Da Literatura como Interpretação de Portugal. O Labirinto da Saudade. 2.ed. Lisboa: Dom Quixote, 1982. p. 85- 126.

MATOS, A. Campos. A Cidade e as Serras. Dicionário de Eça de Queiroz. Lisboa: Caminho, 1988.p.146-148.

MEDINA, João. D. Jacinto em ftaca. Eça Político. Lisboa: Seara Nova, 1974. p. 113-153.

OLIVEIRA, Paulo F. M. Entre Portugal e a Europa: "Civilização" e o Saudosismo. 150 anos com Ef̧a de Queirós - Anais do III Encontro Internacional de Queirosianos. São Paulo: Centros de Estudos Portugueses da USP, 1997.p. 679-684.

PIWNIK, Marie-Helene. Un pamphete contre le Symbolo-Decadentisme:A Cidade e as Serras. Arquivos do Centro Cultural Português, XXIII. Lisboa-Paris: Fundação Calouste Gulbenkian, 1987. p.737-751. 
QUEIRÓS, Eça.A Cidade e as Serras. Porto: Lello \& Irmão, 1950.

QUEIRÓS, Eça.A llustre Casa de Ramires. Porto: Lello \& Irmāo, 1951.

QUEIRÓS, Eça. Brasil e Portugal. Notas Contemporâneas. Porto: Lello \& Irmão, 1945. p.55-90.

QUEIRÓS, Eça. Civilizaçāo. Contos. Porto: Lello \& Immão, 1951.p. 79-1 12.

QUEIRÓS, Eça. Correspondência. Porto: Lello \& Irmão, 1946.

QUEIRÓS, Eça. O Francesismo. Últimas Páginas. Porto: Lello \& Irmão, 1946. p. $397-425$.

QUENTAL, Antero.Causas da Decadência dos Povos Peninsulares nos Últimos Três Séculos. Prosas Sócio-Políticas. Lisboa: Imprensa Nacional - Casa da Moeda, 1982. p. 255-296.

REIS, Carlos. III parte, Capítulo II: Homodiegese: do Conde d'Abranhos à Cidade e as Serras. Estatuto e Perspectivas do Narrador na Fiç̧āo de Eça de Queirós. 3. ed. Coimbra: Almedina, 1984. p.211-245.

SARAIVA, António José.O manto da fantasia. A Tertúlia Ocidental. Lisboa: Gradiva, 1990.p.149-157.

SÉRGIO, António. Notas sobre a imaginaçāo, a fantasia e o problema psicológico-moral na obra novelística de Queirós. Ensaios Tomo VI.3.ed. Lisboa, Sá da Cosra, 1980. p. 53-120.

SOUSA, Frank F. ZÉ Fernandes, personagem narrador de A Cidade e as Serras de Eça de Queirós.Queirosiana, 4. Tormes, Associaçāo dos Amigos de Eça de Queirós, julho 1993. p.13-42.

TORRES, Alexandre Pinheiro. A Cidade e as Serras e as falsas soluçōes sociais do socialismo utópico proudhonista e do socialismo burguês de hoje. Ensaios EscoIhidos I. Lisboa: Caminho, 1989. p. 51-69.

Boletim do CESP v. 17, n.21, jan. / dez. 1997 